\title{
Pengaruh Kemampuan Guru PAI dan Keterampilan Mengelola Kelas Terhadap Peningkatan Adversity Quotient Siswa Kelas XII SMK Negeri 2 Kota Pangkalpinang
}

\author{
Yodea Putri Utami' ${ }^{1}$ Yusra jamali ${ }^{2}$, Nurul Faqih Isro'i ${ }^{3}$ \\ ${ }^{1}$ IAIN Syaikh Abdurrahman Siddik Bangka Belitung \\ 2 IAIN Syaikh Abdurrahman Siddik Bangka Belitung \\ 3 IAIN Syaikh Abdurrahman Siddik Bangka Belitung
}

\author{
Info Artikel : \\ Diterima 12 Maret, 2020 \\ Direvisi 2 April, 2020 \\ Dipublikasikan 31 Mei 2020
}

\section{Kata Kunci:}

Kemampuan Guru PAI,

Ketetampilan Mengelola Kelas,

Adversity Quotient Siswa

\section{Keywords:}

PAI Teacher Ability, Classroom Management Skills, Student Adversity Quotient

\begin{abstract}
ABSTRAK
Penelitian ini bertujuan untuk mengetahui (1) Pengaruh kemampuan guru PAI terhadap peningkatan adversity quotient siswa, (2) Pengaruh keterampilan guru PAI mengelola kelas terhadap peningkatan adversity quotient siswa, (3) Pengaruh secara bersama-sama antara kemampuan guru PAI dan keterampilan mengelola kelas terhadap adversity quotient siswa. Penelitian ini dilakukan di SMK Negeri 2 Kota Pangkalpinang. Penelitian ini merupakan penelitian kuantitatif Subjek yang dianalisis dalam penelitian ini sebanyak 205 orang siswa yang mengacu pada pengambilan sampel dari tabel Morgan dan Krejcie. Hasil penelitian ini menunjukan: (1) Terdapat pengaruh positif dan signifikan kemampuan guru PAI terhadap adversity quotient siswa SMK Negeri 2 Kota Pangkalpinang. (2) Terdapat Pengaruh positif dan signifikan keterampilan mengelola kelas terhadap adversity quotient siswa SMK Negeri 2 Kota Pangkalpinang. (3) Terdapat pengaruh positif dan signifikan antara kemampuan guru PAI dan keterampilan mengelola kelas terhadap peningkatan adversity quotient siswa SMK Negeri 2 Kota Pangkalpinang
\end{abstract}

\section{ABSTRACT}

This study aims to determine (1) the effect of the ability of PAI teachers to increase student adversity quotient, (2) the effect of PAI teacher skills in managing classes on the improvement of students' adversity quotient, (3) the influence together between the ability of PAI teachers and the skills of managing class against student adversity quotient. This research was conducted at SMK Negeri 2 Pangkalpinang City. This research is a kuantitatif research. Subjects analyzed in this study were 205 students who referred to sampling from the Morgan and Krejcie tables.. The results of this study indicate: (1) There is a positive and significant influence on the ability of PAI teachers to adversity quotient of SMK Negeri 2 Kota Pangkalpinang students. (2) There is a positive and significant influence of classroom management skills on the adversity quotient of students of SMK Negeri 2 Pangkalpinang City. (3) There is a positive and significant influence between the ability of PAI teachers and the skills to manage classes on the improvement of adversity quotient of students of SMK Negeri 2 Kota Pangkalpinang

This is an open access article distributed under the Creative Commons Attribution License, which permits unrestricted use, distribution, and reproduction in any medium, provided the original work is properly cited. (2) 2019 by author.

\section{Koresponden:}

Yodea Putri Utami

Email: yodeapu3@gmail.com 
Salah satu cara untuk mencapai tujuan pendidikan adalah melalui belajar di sekolah. Belajar merupakan suatu proses usaha yang dilakukan individu untuk perubahan tingkah laku yang baru secara keseluruhan kearah yang lebih baik lagi. ${ }^{1}$ Proses perubahan perilaku dari yang tidak tahu menjadi tahu dan yang tidak bisa menjadi bisa serta yang tidak paham menjadi paham. Guru mempunyai tugas yang berat dalam mengatarkan anak-anak bangsa ke puncak cita-cita. Untuk dapat menjalankan tugasnya dengan baik, maka seorang guru selayaknya memiliki kualifikasi akademik dan kemampuan yang berkaitan dengan tugas dan tanggung jawabnya. Dengan adanya kualifikasi dan kompentensi tersebut diharapkan seorang guru menjadi tenaga pendidik dan pengajar yang profesional. ${ }^{2}$

Jika seorang guru menginginkan agar tujuan pengajaran tercapai secara efektif dan efisien, bukan kemampuan guru saja yang harus ia miliki, namun guru pun dituntut untuk dapat memiliki kreativitas dan keterampilan dalam melakukan pengelolaan kelas. Karena, selama ini masalah pokok yang terjadi dalam proses belajar mengajar, baik itu guru pemula maupun yang sudah berpengalaman adalah dalam pengelolaan kelas. Dalam perannya sebagai pengelola kelas, guru hendaknya mampu mengelola kelas sebagai lingkungan belajar serta merupakan aspek dari lingkungan sekolah yang perlu di organisasi. Lingkungan ini diatur dan diawasi agar kegiatan-kegiatan belajar terarah kepada tujuan-tujuan pendidikan, karena lingkungan yang baik adalah yang bersifat menantang dan merangsang siswa untuk belajar.

Sejalan dengan pemaparan di atas, pembelajaran dengan kemampuan guru dalam mengelola kelas sudah diterapkan di SMK Negeri 2 Kota Pangkalpinang khususnya pada mata pelajaran PAI di kelas XII. Pada penerapannya di kelas, guru melakukan pengelolaan kelas dengan memusatkan perhatian siswa, mengadakan diskusi kelompok, memberikan contoh-contoh peristiwa yang ada disekitar siswa. Mengelola kelas yang efektif merupakan prasyarat yang mutlak bagi terjadinya proses belajar mengajar yang efektif. ${ }^{3}$ Untuk itu perlu adanya perubahaan kebiasaan dalam cara mengajar guru yang diharapkan akan berpengaruh pada cara belajar siswa. ${ }^{4}$ Dan jika proses belajar mengajar itu efektif, maka materi pelajaran dapat tersampaikan secara maksimal dan tujuan pembelajaran dapat dicapai secara efektif juga. Hal ini juga dapat meningkatkan beberapa kemampuan kecerdasan pada diri siswa.Setiap siswa memiliki macammacam kecerdasan, salah satunya adalah adversity quotient. Adversity quotient merupakan bentuk kecerdasan yang melatarbelakangi kesuksesan seseorang dalam menghadapi sebuah tantangan disaat terjadi kesulitan dan kegagalan. ${ }^{5}$ Kecerdasaan ini perlu kita tingkatkan pada diri siswa agar mereka memiliki motivasi yang tinggi untuk belajar, memiliki keuletan dalam belajar dan memiliki cara-cara belajar yang efektif khususnya pada mata pelajaran Pendidikan Agama Islam (PAI).

Berdasarkan pengalaman peneliti saat melakukan PPLK di SMK Negeri 2 Kota Pangkalpinang dan pra riset yang peneliti lakukan dengan siswa pada tanggal 21 Oktober 2018, sebanyak 22 dari 30 siswa merasa kalau pelajaran PAI terkesan menimbulkan kejenuhan, bosan dan terlalu tegang, sehingga ketika guru menjelaskan mereka tidak terlalu mempeRhatikan dan pada akhirnya ketika guru hendak bertanya menyebabkan mereka sering merasakan kurang percaya diri dengan kemampuan yang mereka miliki. Mereka juga menganggap bahwa soal dan tugas diberikan guru terlalu banyak dan sulit sehingga menyebabkan mereka hanya mengandalkan temannya yang mereka anggap bisa untuk mengerjakan soal atau tugas tersebut. ${ }^{6}$

Kemampuan merupakan kapasitas seseorang individu untuk melakukan beragam tugas dalam suatu pekerjaan. Kemampuan (ability) adalah sebuah penilaian terkini atas apa yang dapat dilakukan seseorang ${ }^{7}$. Sedangkan Muhammad Zain mengartikan bahwa kemampuan adalah kesanggupan, kecakapan, kekuatan berusaha dengan diri sendiri. ${ }^{8}$ Sementara kemampuan guru menurut Ustman Uzer ialah adalah kecapakan atau potensi sesorang individu untuk menguasai keahlian dalam mengelola kelas dalam rangka memberikan ilmu pengetahuan kepada peserta didik agar mencapai tingkat kedewasaan. ${ }^{9}$ Maka dari itu kemampuan bisa disimpulkan sebagai kesanggupan, kecakapan dan kekuatan seseorang dalam melaksanakan tugas untuk memenuhi suatu tujuan guna mendapatkan hasil yang maksimal. Kemampuan guru dalam suatu bidang pendidikan guru merupakan hal yang paling utama. Dimana guru menjadi fasilitator, penunjang, pembimbing dan penentu arah bagi kemampuan bagi para siswanya.

\footnotetext{
${ }^{1}$ Stefanus M. Marbun, Psikologi Pendidikan, (Ponorogo: Uwais Inspirasi Indonesia, 2018), hlm. 141.

${ }^{2}$ Suparlan, Menjadi guru efektif, (Jakarta : Hikayat Publishing, 2008), hlm. 146.

${ }^{3}$ Moh. Uzer Ustman, Menjadi Guru Profesional, (Bandung: PT. Remaja Rosydakarya, 2016), hlm. 97.

${ }^{4}$ Khoiriyah, Menggagas Sosiologi..., hlm. 149.

${ }^{5}$ Paulz G. Stoltz, Adversity Quotient : Mengubah Hambatan Menjadi Peluang, (Jakarta: Grasindo, 2007), hlm. 8

${ }^{6}$ Hasil prariset peneliti dengan siswa, Wawamcara, Tanggal 21 Oktober 2018.

${ }^{7}$ Robbin Steven, Perilaku Organisasi, (Jakarta: Salemba Empat, 2007). Hlm.57.

${ }^{8}$ Milman Yusdi, Kamus Umum Bahasa Indonesia, (Jakarta: Pustaka Sinar Harapan, 2010), hlm, 10.

${ }^{9}$ Moh. Uzer Ustman, Menjadi Guru..., hlm. 15.
} 
Sementara itu, Asosiasi Lembaga Pendidikan Tenaga Kependidikan (ALPTK) dalam kongresnya di Bandung tanggal 19-21 Januari 2006 dan ditindaklanjuti dalam Rapat Kerja di Surabaya tanggal 26-28 Januari 2007 telah merumuskan keempat kompetensi (dimensi kompetensi) guru, dalam rumusan sebagai berikut: ${ }^{10}$ Kompetensi pedagogik merupakan kemampuan mengelola pembelajaran siswa yang meliputi pemahaman terhadap siswa, kemampuan merancang dan melaksanakan pembelajaran, evaluasi hasil belajar, dan pengembangan siswa untuk berbagai potensi yang dimiliki. Kompetensi kepribadian merupakan penguasaan kepribadian yang menjadi teladan bagi peserta didik dan berakhlak mulia dan kemampuan kedisiplinan.Kompetensi profesional merupakan kemampuan penguasaan materi pembelajaran yang memungkinkan membimbing peserta didik memenuhi standar kompetensi dan mengelola proses pembelajaran.Kompetensi sosial merupakan kemampuan berkomunikasi dan berkerja sama dengan masyarakat, sesama pendidik/ tenaga kependidikan lain, orang tua, lingkungan sekolah dan siswa dan kemampuan pengetahuan agama dan adat istiadat.11

Keterampilan mengelola kelas merupakan kemampuan guru untuk menciptakan dan memelihara kondisi belajar yang optimal dan mengembalikannya ke kondisi belajar yang optimal jika terjadi gangguan, baik dengan cara mendisiplinkan ataupun melakukan kegiatan remedial. ${ }^{12}$ Sedangkan, menurut Djamarah dan Zain, pengelolaan kelas adalah kemampuan guru untuk menciptakan dan memelihara kondisi belajar yang optimal dan mengembalikannya jika terjadi gangguan dalam proses belajar mengajar. ${ }^{13}$ Uraian tersebut dapat dipahami bahwa pengelolaan kelas adalah suatu usaha yang sengaja dilakukan guna untuk mencapai tujuan pengajaran. Sehingga dapat disimpulkan bahwa pengelolaan kelas merupakan kegiatan pengaturan kelas untuk kepentingan pengajaran, pengertian lain dari pengelolaan kelas juga dapat dipahami sebagai cara untuk mempertahankan ketertiban kelas.

Adversity quotient juga dapat berarti sebagai bentuk kecerdasan yang melatarbelakangi kesuksesan seseorang dalam menghadapi sebuah tantangan disaat terjadi kesulitan atau kegagalan. ${ }^{14}$ Kesulitan yang dimaksud disini adalah kesulitan belajar karena penelitian ini dalam konteks pendidikan. Dengan $\mathrm{AQ}$ yang tinggi seseorang akan menghadapi persoalan dalam belajar dengan tidak putus asa. Jadi dapat disimpulkan bahwa pada dasarnya adversity quotient merupakan kemampuan seseorang dalam mengatasi kesulitan untuk mencapai sesuatu yang tinggi menurut ukuran kemampuan yang dimiliki seseorang secara terus menerus. Adversity quotient mempunyai tiga bentuk. Pertama, adversity quotient merupakan suatu kerangka kerja konseptual yang baru untuk memahami dan meningkatkan semua segi kesuksesan. Kedua, adversity quotient berarti sebagai suatu ukuran untuk mengetahui respons anda terhadap kesulitan. Ketiga, adversity quotient berarti serangkaian peralatan yang memiliki dasar ilmiah untuk memperbaiki respon anda terhadap kesulitan, yang berakibat memperbaiki efektifitas pribadi dan profesional individu secara keseluruhan."15

Stotz menyebutkan empat dimensi yang menyusun adversity quotient seseorang yaitu CO2RE (control, origin, ownership, Reach Endurance) dijelaskan yakni kendali diri (Control) kemampuan individu dalam mempengaruhi secara positif suatu situasi, serta mampu mengendalikan respon terhadap situasi, Asal-usul dan pengakuan (origin dan ownership) Dimensi ini mempunyai keterkaitan dengan rasa bersalah. Dengan mengetahui dan faham tentang asal-usul dari sebuah permasalahan maka akan merasa yakin terhadap pengakuan dirinya untuk dapat membereskan dan cepat menyelesaikan permasalahan yang ada. Reach merupakan kemampuan individu dalam menjangkau dan membatasi masalah agar tidak menjangkau bidang-bidang yang lain dari kehidupan individu. Daya tahan (endurance) dimensi ini lebih berkaitan dengan persepsi seseorang akan lama atau tidaknya kesulitan akan berlangsung.

\section{METODE}

Metode yang digunakan dalam penelitian kuantitatif ini adalah metode survei. Metode survei adalah metode yang digunakan untuk mengumpulkan data atau informasi tentang populasi yang besar dengan menggunakan sampel yang relatif kecil. Survei ditujukan untuk memperoleh gambaran umum tentang karakteristik populasi tersebut.

Populasi dan Sampel

Populasi adalah kelompok dimana seseorang peneliti akan memperoleh hasil penelitian yang dapat disamaratakan (digeneralisasikan). Suatu populasi mempunyai sekurang-kurangnya satu karakteristik yang membedakan populasi itu dengan kelompok-kelompok lain. ${ }^{16}$ Berdasarkan beberapa

\footnotetext{
${ }^{10}$ Ibid, hlm. 24.

11 Ibid, hlm. 25.

${ }^{12}$ Hasibuan, Proses Belajar Mengajar..., Hlm. 82.

${ }^{13}$ Syaiful Bahri Djamarah dan Aswan Zain, Strategi Belajar..., Hlm. 173.

14 Ibid.

15 Paul G. Stoltz, Adversity Quotient Mengubah... hlm. 9.

${ }^{16}$ Hamid Darmadi, Metodologi Penelitian,נ,. hlm. 46
} 
pengertian mengenai populasi penelitian, maka yang menjadi populasi target dalam penelitian ini adalah keseluruhan siswi kelas XII di SMK Negeri 2 Kota Pangkalpinang yang seluruhnya berjumlah 445 orang, dengan pengambilan sampel pada populasi berdasarkan teknik simple random sampling.

Menurut Sugiyono sebagaimana yang dikutip oleh Kasmadi dan Nia Siti Sunariah, sampel adalah sebagian dari jumlah dan karakteristik yang dimiliki oleh populasi tersebut. Penelitian ini peneliti merujuk pada tabel jumlah sampel berdasarkan tabel Krejcie dan Morgan yaitu apabila jumlah populasinya 445 orang, maka taraf kepercayaan 95\% yaitu sebanyak 205 orang. Maka, sampel dalam penelitian ini adalah sebanyak 205 sampel.

Uji Instrumen Penelitian

1. Validitas

Validitas adalah tingkat keandalan dan kesahihan alat ukur yang digunakan. Instrumen dikatakan valid berarti menunjukkan alat ukur yang dipergunakan untuk mendapatkan data itu valid atau dapat digunakan untuk mengukur apa yang seharusnya di ukur. ${ }^{17}$ Angket uji coba dalam penelitian ini ditujukan kepada siswa di SMA Negeri 2 Kota Pangkalpinang sebanyak 30 orang.

Pengujian angket ini terlebih dahulu dicari harga korelasi antara bagian-bagian dari alat ukur secara keseluruhan dengan cara mengkorelasikan setiap butir alat ukur dengan skor total yang merupakan jumlah tiap skor butir dengan rumus pearson product moment sebagai berikut ${ }^{18}$ :

keterangan:

$$
r_{\text {hitung }}=\frac{n\left(\sum X Y\right)-\left(\sum X\right) \cdot\left(\sum Y\right)}{\sqrt{\left\{n \cdot \sum X^{2}-\left(\sum X\right)^{2}\right\}} \cdot \sqrt{\left\{n \cdot \sum Y^{2}-\left(\sum Y\right)^{2}\right\}}}
$$

$r_{\text {hitung }}=$ koefisien korelasi

$\sum X \quad=$ jumlah skor item

$\sum Y \quad=$ skor total (seluruh soal untuk setiap responden)

$\mathrm{n} \quad$ = banyaknya responden

Kriteria validitasnya adalah: valid jika " $\mathrm{r}_{\text {hitung }}>\mathrm{r}_{\text {tabel" }}$ "

Distribusi (tabel t) untuk $\alpha=0,05$ dan derajat keabsahan ( $\mathrm{dk}=\mathrm{n}-2)$.

2. Realibilitas

Suatu intrumen pengukuran dikatakan reliabilitas jika pengukurannya konsisten dengan cermat akurat dengan tujuan utama untuk mengetahui konsistensi dari intrumen sebagai alat ukur, sehingga hasil suatu pengukuran dapat dipercaya. ${ }^{19}$ Rumus yang digunakan adalah korelasi alpha cronbach:

Keterangan:

$$
\mathrm{R}=\left(\frac{n}{n-1}\right)\left(1-\frac{\sum s_{i}}{S_{t}}\right)
$$

$\mathrm{r}_{11} \quad$ : reliabilitas

n : jumlah item yang valid

$\sum S_{i} \quad$ : jumlah varians skor tiap-tiap item

$S_{t} \quad$ : varians total

kriteria reliabilitasnya adalah jika " $\mathrm{r}_{\text {hitung }} \mathrm{r}_{\text {tabel"] }}$

Teknik Analisis Data

Penelitian ini menggunakan analisis deskriptif, teknik analisis regresi sederhana dan regresi linier berganda. Analisis deskriptif digunakan untuk menjelaskan aspek demografis responden, tingkat kemampuan guru, tingkat keterampilan guru mengelola kelas dan tingkat adversity quotient siswa. Analisis regresi sederhana untuk mengukur pengaruh antara variabel $\mathrm{x} 1$ dengan y dan variabel x2 dengan $\mathrm{y}$. Sementara regresi linier berganda untuk mengukur seberapa besar pengaruh kedua variabel $\mathrm{x} 1, \mathrm{x} 2$ dengan y.

Sebelum melakukan uji regresi sederhana dan berganda maka perlu dilakukan uji asumsi klasik (normalitas, linieritas, heterokedastisitas dan auto korelasi). Uji normalitas yang diperoleh diketahui bahwa nilai Sig. (2-tailed) variabel sebesar 0,2 yang artinya nilai Sig. (2-tailed) lebih besar dari 0,05. Sehingga dapat disimpulkan bahwa seluruh data dalam penelitian ini berdistribusi normal. Pengambilan keputusan melihat kriteria nilai F hitung $<$ F tabel, untuk X1 $(1,09<1,39)$ dan X2 $(1,34<1,39)$ pada taraf signifikan $5 \%$ maka dapat disimpulkan, ada hubungan yang linier antara variabel bebas dengan variabel terikat, yang berarti variabel bebas meningkat diikuti oleh meningkatnya variabel terikat dan memungkinkan untuk menggunakan analisis regresi. Berdasarkan uji multikolinieritas sebagaimana pada

\footnotetext{
${ }^{17}$ Anas Sudijono, Pengantar Statistik Pendidikan, (Jakarta: Raja grafindo Persada, 2011), hlm. 206.

18 Riduwan, Belajar Mudah...,hlm. 98.

19 Ibid., hlm. 102.
} 
tabel dapat dilihat bahwa nilai untuk nilai variabel kemampuan guru PAI dan keterampilan mengelola kelas sebesar 2,357. Maka, dapat disimpulkan bahwa variabel terbebas dari multikoliniearitas, karena nilai VIF untuk setiap variabel kurang dari atau tidak lebih besar dari 10. Uji Heterokedastisitas berdasarkan hasil output SPSS, variabel kemampuan guru PAI memiliki nilai Sig. (2-tailed) 0,752 >0,05 dan variabel keterampilan guru PAI mengelola kelas memiliki nilai Sig. (2-tailed) 0,551 >0,05. Dari hasil tersebut dapat disimpulkan bahwa variabel yang diuji tidak mengandung heteroskedastisitas. Hasil perhitungan autokorelasi bahwa nilai DW sebesar 2,004 terletak antara nilai du dan (4-du) sebesar 1,77852 dan 2,22148 (du < DW < 4-du), maka dapat disimpulkan bahwa tidak ada autokorelasi dalam model regresi yang digunakan dalam penelitian ini.

\section{HASIL DAN PEMBAHASAN}

Berdasarkan data tanggapan responden mengenai data kemampuan guru PAI, dapat dilihat bahwa guru memiliki kecenderungan kemampuan yang tinggi sebesar $69,8 \%$, sedangkan memiliki kecenderungan kemampuan yang sedang sebesar $29,8 \%$ dan rendah sebesar $0 \%$. Dengan melihat kecenderungan skor pada variabel kemampuan guru PAI, dapat disimpulkan bahwa variabel kemampuan guru PAI SMK Negeri 2 Kota Pangkalpinang termasuk kategori tinggi. Sedangkan kecenderungan keterampilan mengelola kelas yang tinggi sebesar $45,9 \%$, sedangkan memiliki kecenderungan kemampuan yang sedang sebesar $54,1 \%$ dan rendah sebesar $0 \%$. Dengan melihat kecenderungan skor pada variabel kemampuan guru PAI, dapat disimpulkan bahwa variabel keterampilan mengelola kelas SMK Negeri 2 Kota Pangkalpinang termasuk kategori sedang.Sementara tingkat kecenderungan adversity quotient yang tinggi sebesar $24,4 \%$ atau 50 siswa, sedangkan kecenderungan adversity quotient siswa yang sedang sebesar $75,1 \%$ atau 154 siswa dan rendah sebesar 5\% atau 1 siswa. Dengan melihat kecenderungan skor pada variabel adversity quotient siswa, dapat disimpulkan bahwa variabel adversity quotient siswa SMK Negeri 2 Kota Pangkalpinang termasuk kategori sedang.

Setelah diperoleh data dan diketahui bagaimana hasil pengukuran kemampuan guru PAI, keterampilan mengelola kelas dan adversity quotient siswa SMK Negeri 2 Kota Pangkalpinang. Berikutnya yang perlu diketahui adalah bagaimana pengaruh kemampuan guru PAI terhadap peningkatan adversity quotient siswa, pengaruh keterampilan mengelola kelas terhadap adversity quotient siswa dan pengaruh kemampuan guru PAI dan keterampilan mengelola kelas dan adversity quotient siswa SMK Negeri 2 Kota Pangkalpinang. Berdasarkan hasil uji hipotesis 1 di atas diketahui bahwa kemampuan guru PAI berpengaruh positif dan signifikan terhadap adversity quotient siswa yang ditunjukkan dengan hasil uji $t$ diperoleh harga thitung sebesar 9,493 dengan tingkat signifikansi sebesar 0,000 jika dibandingan dengan ttabel 1,971 maka thitung $>$ ttabel dan $\rho<0.05$. Hal ini menunjukan bahwa H1 diterima dan H0 ditolak, dengan koefisien determinan 0,307 sehingga dapat disimpulkan kemampuan guru PAI memberikan pengaruh terhadap peningkatan adversity quotient siswa sebesar $30,7 \%$.

Sedangkan hasil uji hipotesis 2, keterampilan guru mengelola kelas berpengaruh signifikan terhadap adversity quotient siswa berdasarkan hasil uji $\mathrm{t}$ yang telah dilakukan yaitu thitung $>\mathrm{t}$ tabel $=$ 15,092 > 1,971 dengan nilai analisis Sig. yaitu 0,000 < 0,05 maka, H0 ditolak dan H1 diterima. Dapat disimpulkan bahwa keterampilan guru mengelola kelas berperngaruh sginifikan terhadap peningkatan adversity quotient siswa. Sementara, kemampuan guru PAI dan Keterampilan Mengelola Kelas secara bersama-sama mempunyai pengaruh yang signifikan terhadap adversity quotient siswa dengan dibuktikan dengan uji F yaitu F hitung $>$ F tabel yaitu 113,329 > 3,04 dan nilai Sig. $<0,050$ yaitu 0,000 <0,050. Sedangkan sumbangan efektif kedua variabel terhadap adversity quotient siswa adalah 52,9\%, yang berarti sebesar 52,9\% variabel adversity quotient siswa dipengaruhi oleh kemampuan guru PAI dan keterampilan guru mengelola kelas dan $47,1 \%$ dipengaruhi oleh variabel lain.

\section{KESIMPULAN}

Berdasarkan hasil penelitian terdapat pengaruh yang positif dan signifikan antara kemampuan guru PAI terhadap adversity quotient siswa, terdapat pengaruh yang positif dan signifikan antara keterampilan guru PAI mengelola kelas terhadap adversity quotient siswa dan terdapat pengaruh yang positif dan signifikan secara bersama-sama antara kemampuan guru PAI terhadap adversity quotient siswa. 


\section{REFERENSI}

Abdul Halim, Soebahar. 2009. Matriks Pendidikan Islam. Yogyakarta: Pustaka Marwa.

Ar-Rifa'i, Muhammad Nasib. 2015. Kemudahan dari Allah Ringkasan Tafsir Ibnu Katsir Jilid 4. Jakarta: Gema Insani.

Arikunto, Suharsimi. 1996. Pengelolaan Kelas Dan Siswa Sebuah Pendekatan Evaluatif. Jakarta: PT. Raja Grafindo.

Aslichati. 2011. Etos Kerja dan Kita. Jakarta : Universitas Terbuka.

Azhar, Iman. 2013. Pengelolaan Kelas dari Teori ke Praktek. Yogyakarta: Insyira.

Azwar, Seafudin. 2004. Metode Penelitian. Yogyakarta: Pustaka Pelajar.

Bungin, Burhan. 2017. Metodologi Penelitian Kuantitatif. Jakarta: Kencana.

Darmadi, Hamid. 2011. Metodologi Penelitian Pendidikan. Bandung: Alfabeta.

Djamarah, Syaiful Bahri. 2002. Psikologi Belajar. Jakarta: PT. Rineka Cipta.

Ghozali. 2013. Aplikasi Analisis Multivariate Dengan Program IBM SPSS 21 Edisi 7. Semarang, Badan Penerbit Universitas Diponegoro.Harsanto, Radno. 2007. Pengelolaan kelas yang Dinamis. Yogyakarta : Kanisius.

Husamah dkk. 2018. Belajar dan Pembelajaran. Malang: UMM Pers.

Khoiriyah. 2014. Menggagas Sosiologi Pendidikan Islam. Yogyakarta: Teras.

Kunandar. 2007. Guru Profesional. Jakarta: PT Raja Grafindo.

Majid, Abdul. 2008. Perencanaan Pembelajaran Mengembangkan Standar Kompetensi Guru. Bandung, PT. Remaja Rosda Karya.

Marbun, Stefanus. 2018. Psikologi Pendidikan. Ponorogo: Uwais Inspirasi Indonesia.

Muslich, Muhammad. 2009. Metode Pengambilan Keputusan Kuantitatif. Jakarta : Bumi Aksara.

Nurgiyantoro, Burhan Gunawan, \& Marzuki. 2004. Statistik Terapan: Untuk Penelitian Ilmu-Ilmu Sosial.

Yogyakarta, Gadjah Mada University Press.

Rasyad, Rasdihan. 2003. Metode Statistik Deskriptif Untuk Umum. Yogyakarta: PT. Grasindo.

Rohani Ahmad, dan Abu Ahmadi. 2003. Pengelolaan Pengajaran. Jakarta : Rineka Cipta.

Rusman. 2012. Model-model pembelajaran. Jakarta : Raja Grafindo Persada.

Saifuddin. 2018. Pengelolaan Pembelajaran Teoritis dan Praktis. Yogyakarta: Deepublish.

Santosa. 2018. Statistika Hospitalitas. Yogyakarta: CV. Budi Utama.

Sardiman. 2011. Interaksi dan Motivasi Belajar Mengajar. Jakarta : PT. Raja Grafindo Persada.

Sarwono, Jonathan. 2015. Membuat Skripsi, Thesis Dan Disertai Partial Least Aquare SEM (PLS-SEM). ANDI, Yogyakarta.

Siregar, Eveline dan Hartini Nara. 2011. Teori Belajar dan Pembelajaran. Bogor: Ghalia Indonesia.

Siregar, Syofian. 2013. Statistik Parametrik untuk Penelitian Kuantitatif: Dilengkapi dengan Perhitungan Manual dan Aplikasi SPSS Versi 17. Jakarta: Kencana Prenada Media Group.

Steven, Robbin. 2007. Perilaku Organisasi. Jakarta: Salemba Empat.

Stoltz, Paul G. 2007. Adversity Quotient: Mengubah Hambatan Menjadi Peluang. Jakarta: Grasindo.

Sudijono, Anas. 2011. Pengantar Statistik Pendidikan. Jakarta: Raja grafindo Persada.

Sujarweni, V. Wiratna. 2014. Metodologi Penelitian : Lengkap, Praktis, dan Mudah Dipahami. Yogyakarta, Pustaka Baru Press.

Sujianto, Agus Eko. 2009. Aplikasi Statistik dengan SPSS 16. Jakarta : Prestasi Pustaka.

Sukmadinata, Nana Syaodih. 2011. Metode Penelitian Pendidikan. Bandung: PT Remaja Rosdakarya.

Suparlan. 2008. Menjadi guru efektif. jakarta : Hikayat Publishing.

Sugiyono. 2014. Metode Penelitian Kualitatif dan R\&D. Bandung: Alpabeta.

Syaiful Bahri dan Aswan Zain, Manajemen Pendidikan. Universitas Negeri

Syukri \& Marwawi. 2012. Pengantar Pendidikan. Pontianak: STAIN Pontianak press.

Umar. 2019. Pengantar Profesi Keguruan. Jakarta : Rajawali Pers.

Ustman, Moh. Uzer. 2016. Menjadi Guru Profesional. Bandung: PT. Remaja Rosydakarya.

Wijaya, Iwan. 2018. Professional Teacher: Menjadi Guru Profesional. Sukabumi : CV Jejak.

Wijaya, L. Tri dan Debrina. 2016. Aplikasi Komputer dan Pengolahan Data. Malang: UB Press.

Yusdi, Milman. 2010. Kamus Umum Bahasa Indonesia. Jakarta: Pustaka Sinar Harapan. 